\title{
Diversification of "NAJWA" Hijab Staining using Tie-Dye Method Based on Natural Dyes
}

\author{
Samik \\ Chemistry Departement \\ Universitas Negeri Surabaya \\ Surabaya, Indonesia \\ samik@unesa.ac.id
}

\author{
Agus Budi Santoso \\ Electrical Engineering Departement \\ Universitas Negeri Surabaya \\ Surabaya, Indonesia \\ agusbudisantoso@unesa.ac.id
}

\author{
Nita Kusumawati* \\ Chemistry Departement \\ Universitas Negeri Surabaya \\ Surabaya, Indonesia \\ nitakusumawati@unesa.ac.id
}

\begin{abstract}
Diversification of "Najwa" hijab staining has been carried out using a tie-dye method based on natural dyes. A number of natural dyes materials, which include turmeric, cherry and mango leaves and brazilwood bark, have been optimized for use. To obtain a stable color quality, staining is carried out preceded by the pre-treatment (washing and mordanting) and ending with fixation using alum, lime and iron (II) sulfate. The results of the staining show the appearance of reddish (blush) color on the combination of cherry leaves-brazilwood bark, and brown (nutella) on the brazilwood bark-turmeric. Meanwhile, the application of different fixers has resulted in the appearance of different color shades on the combination of mango leaves-turmeric, namely orange (mustard) produced by alum fixers and dark green (dark army) produced by iron (II) sulfate fixers. To improve the quality of the hijab color, the color intensity and fastness resulting from multilevel staining and fixation were also evaluated.
\end{abstract}

Keywords-Hijab, Najwa, Tie-dye, natural dye

\section{INTRODUCTION}

Hijab is a basic and primary requirement for Muslim women. In addition to being useful to cover the nakedness, the hijab is also a supporting component of the appearance of Muslim women in everyday life. As an inseparable part of the fashion industry, the movement of hijab trends is also very dynamic. This condition makes the hijab industry as one of the most developed creative industries today.

All hijab products sold in the market offer the beauty of Islamic clothing and the elegance of Muslim women. But of all the hijab products in circulation, no one has brought the concept of natural staining. Intensive fashion production, one of which is hijab, which depends on the presence of synthetic dyes has triggered high levels of water pollution and damage to the equilibrium of the global ecosystem [1][2]. Synthetic dyes also cause skin disease as well as eye, bone and liver damage [3]-[4]. In this regard, many consumers are faced with a number of different health problems after the use of textile products with synthetic dyes [5].

"Najwa" is one of the hijab businesses that also feels this. Since its foundation in Jember city, this hijab business has developed quite well. Starting from just distributing hijab products from a number of producers, currently this SMEs has succeeded in producing its own hijab under the brand name "Najwa". In its development, this SMEs has sought to diversify its hijab products, one of which is by producing natural color hijab. However, due to the lack of knowledge and skills in natural staining, the color quality of "Najwa" hijab products is less stable and homogeneous and has low fastness. In cases like this, it is important to standardize each stage in natural staining.

A number of Indonesian local commodities are reported to have potential as natural dyes, not to mention the leaves waste from plants such as cherry and mango. Cherry leaves contain compounds flavonoids, tannins, triterpenoids, saponins, and polyphenols which show anti-oxidative and anti-microbial activity. On the other hand, cherry leaves can be used as natural dyes because they contain flavonoids and tannins that provide color. In contrast to cherry leaves, mango leaves contain pigment mangiferin, which is an unsaturated and aromatic hydrocarbon compound that forms a $\mathrm{C}=\mathrm{O}$ chromophore group and $-\mathrm{OH}$ auxochrome group, of $7-15 \%$. In addition to both, turmeric and brazilwood bark are local potentials of Indonesia which also has the potential to be used as textile natural dyes. Turmeric has long been used as a producer of natural yellow-orange colors. This color is produced by the curcuminoid group, which includes curcumin, demetoxy curcumin, and bis-demetoxy curcumin. While in brazilwood bark, the brazilin pigment content which is able to bring out the characteristic red color shades has made this material the potential to be further developed as a textile natural dye [6]-[7].

Tie-dye is a staining method in which a part of a fabric piece is conditioned in such a way and then tied with elastic straps or ribbons. When dyeing is done, the part of the fabric that is not bound will tend to be saturated with the dye, while the part that is bound, will relatively reject the color. In this staining method, the bond acts as a dyes resist. With this staining method, beautiful color overlapping motifs can be formed [8].

\section{MATERIAL AND METHODS}

\section{A. Material}

For the fabrication of natural dyes using the tie-dye method, the fabric used by Najwa SMEs is a type of hero fabric, obtained from the Moro Seneng Fabric Shop (Surabaya, Indonesia). To get the staining results with shades according to the target and high color intensity, a pre- 
treatment was carried out using Turkey Red Oil (TRO, $\geqslant$ $70 \%$, alum $\left(\mathrm{Al}_{2}\left(\mathrm{SO}_{4}\right)_{3} \cdot 18 \mathrm{H}_{2} \mathrm{O}, \geqslant 17 \%\right)$ and soda ash $\left(\mathrm{Na}_{2} \mathrm{CO}_{3}, \geqslant 48 \%\right)$. Natural dye extracts were prepared by Najwa SMEs using cherry and mango leaves obtained from the environment around the business location, as well as turmeric and brazilwood bark obtained from the local market in Jember. Color locking is done at the final stage of the process by using 3 types of fixers, namely alum with the same specifications as those used in the mordanting, lime $(\mathrm{CaO}, \geqslant 90 \%)$ stages obtained from Mitra Water and iron (II) sulfate $\left(\mathrm{FeSO}_{4} .7 \mathrm{H}_{2} \mathrm{O}, \mathrm{d} 2.84 \mathrm{~g} / \mathrm{cm}^{3}\right)$ obtained from PT. Nusa Indah Megah (Surabaya, Indonesia).

\section{B. Pre-treatment}

Before going through the staining stage, the fabric raw materials go through the pre-treatment stage which includes washing and mordanting. Washing is done to remove contaminants, both water and fat based using TRO. TRO solution was prepared by dissolving $0.086 \mathrm{~g}$ TRO in $1 \mathrm{~L}$ of water. As soon as the TRO solution is available, immersion $2.085 \mathrm{~g}$ of fabric in $1,000 \mathrm{~mL}$ TRO. Immersion is carried out for $6 \mathrm{~h}$. To ensure the absence of TRO residues in the fabric fibers, rinse 3 times after each, using $1.9095 \mathrm{~L}$ of water each. The washing step ends with drying the fabric in the open air for $24 \mathrm{~h}$. After that, the fabric is ready for further processing, which is at the mordanting stage.

Mordant was prepared by Najwa SMEs through dissolving $16.08 \mathrm{~g}$ alum and $4.02 \mathrm{~g}$ soda soda in $1.9095 \mathrm{~L}$ water. To optimize the solubility of both in water, stirring for $5 \mathrm{~min}$ and heating to $100^{\circ} \mathrm{C}$. In the next step, the fabric is put into a mordant and allowed to stand for $1 \mathrm{~h}$ will continuing to heat. The fabric immersion in a mordant is continued for 24 $\mathrm{h}$, but this time without heating. To get fabric free from mordant residues, the fabric is rinsed 3 times using water $1.9095 \mathrm{~L}$. The fabric is then dried in the open air for $24 \mathrm{~h}$, and then ironed to get a homogeneous fiber orientation. After that, the fabric is ready to be dyed [9]-[10].

\section{Dyeing}

At this stage, staining is carried out using the tie-dye method. To get the typical tie-dye motif, the fabric that has gone through the mordanting stages, is tied to certain parts using a slap rope and then wrapped in the bonding section using plastic wrap. This is done to optimize the color barrier on the targeted part. The bonding model applied at this staining stage is shown in Fig. 1.

The staining done at this stage follows the composition as shown in Table 1. For this purpose, the dye extract was prepared by Najwa SMEs by heating the dye raw material that has been blended in a water solvent until the volume becomes half of the initial. The resulting dye extract is then filtered using a single layer of fabric, to separate the raw material residues from the extract. Staining is done by immersing $67 \mathrm{~g}$ fabric in $2010 \mathrm{~mL}$ of each dye extract for 5 min and then dried. The same procedure was repeated 4 times and then ended with the first fixation. After drying for the second time, the hijab fabric enters the second staining stage with the same procedure, which is applied 4 times. After that, to get better intensity and fastness, a second fixation was done using a fixer that was able to trigger a darker color. In accordance with the order of the dark color produced, starting from the lowest to the highest successive fixer used is alum, lime and then iron (II) sulfate.
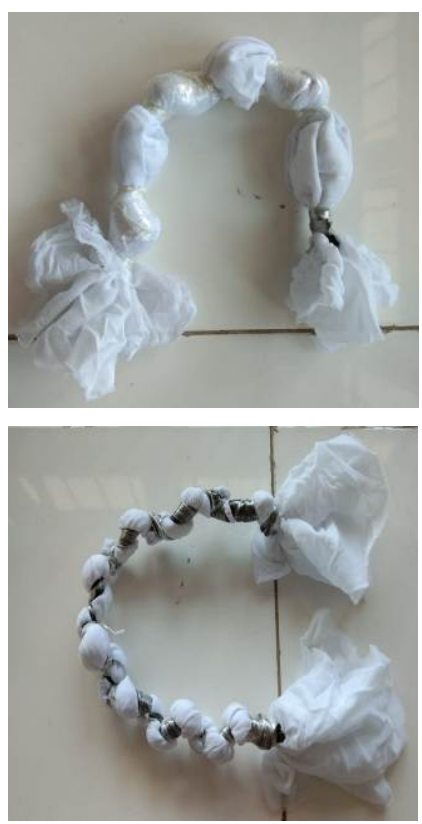

Fig. 1. A typical tie-dye bonding model used for staining

TABLE I.

THE DYES COMPOSITION OF THE NAJWA HIJAB STAINING PROCESS

\begin{tabular}{cccc}
\hline No & Color Type & Dyes Composition & Fixer Type \\
\hline 1 & Blush & $25 \% \mathrm{CL} / 75 \% \mathrm{BWB}$ & Alum \\
\hline 2 & Nuttela & $25 \% \mathrm{~T} / 75 \% \mathrm{BWB}$ & Lime \\
\hline 3 & Mustard & $25 \% \mathrm{ML} / 75 \% \mathrm{~T}$ & Alum \\
\hline 4 & Dark Army & $75 \% \mathrm{ML} / 25 \% \mathrm{~T}$ & Iron (II) sulfate \\
\hline $\begin{array}{l}\text { Note : } \\
\text { CL }=\text { Cherry leaves; BWB }=\text { Brazilwood bark; T }=\text { Turmeric; and ML } \\
\text { Mango leaf. }\end{array}$
\end{tabular}

\section{Fixation}

At this stage, Najwa SMEs prepares 3 fixation solutions, namely alum, lime and iron (II) sulfate. The fixation solution is prepared by dissolving $50 \mathrm{~g}$ of fixer in $1 \mathrm{~L}$ of water. All fixer solutions were prepared using the same composition. The formed solution is then stirred using a magnetic stirrer for $5 \mathrm{~min}$ and then allowed to stand for $24 \mathrm{~h}$, to obtain the transparent portion. This part is then used in the fixing process of the hijab fabric, where $67 \mathrm{~g}$ the fabric is immersed in 2,010 $\mathrm{L}$ fixer for $10 \mathrm{~min}$. To minimize the remaining fixer residue on the fabric fibers, it was washed 3 times, each using $2000 \mathrm{~mL}$ of water. The fixation stage ends with drying in the open air for $24 \mathrm{~h}$.

\section{E. Characterization}

To get the color quality of Najwa hijab after natural staining, the color intensity analysis was performed using Shimadzu UV -2401-PC Diffuse Reflectant Ultraviolet 
(DRUV) Spectrophotometer and color fastness using the Gray Staining Scale method.

\section{RESULT AND DISCUSSIONS}

Tie-dye is a modern term found in thebois for a series of ancient color rejection techniques. The tie-dye process usually consists of folding, twisting, or squeezing the fabric and then binding with a rope, followed by the application of the dye. Fabric manipulation is done to prevent the entry of color in some fabrics. More sophisticated tie-dye involves additional steps, including the application of basic colors before color rejection conditions in certain parts, multilevel staining and color rejection, and the use of other types of color rejection methods (using stitching and stencil methods) as well as removal.

Unlike regular color rejection techniques, tie-dye is characterized by the use of bright, saturated primary colors and bold patterns. However, renewed interest in more 'sophisticated' tie-dye has emerged in the fashion industry, characterized by simple motifs, monochromatic color schemes, and applications in fabrics other than cotton. Whatever type of treatment is used to display specific motifs on the fabric, the success of staining becomes the most important part of tie-dye.

To get the best shade and color quality from the leaves of cherry and mango, turmeric, and brazilwood bark, Najwa SMEs has applied a number of standardized operational stages, including pre-treatment (washing and mordanting), staining and fixation. The pre-treatment method will ensure that the raw material for the fabric is free from contaminants, both water and oil based. Thus, the raw material used will be able to react optimally with mordant, which in this case will act as an intermediary for the reaction of fabric fibers with natural dyes used [11]-[12]. At this stage, washing is carried out by relying on TRO's ability to dissolve polar and nonpolar contaminants, while mordanting is carried out using alum and soda ash. Fig. 1 shows the molecular structure of alum and soda ash, while Fig 2 shows the fabric pretreatment process carried out by Najwa SMEs.

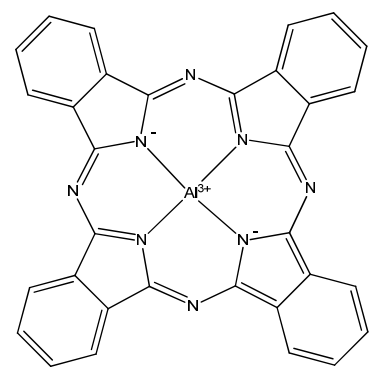

(a)

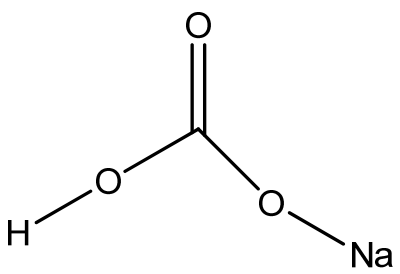

(b)

Fig. 2. Molecular structure of: (a) alum; and (b) soda ash

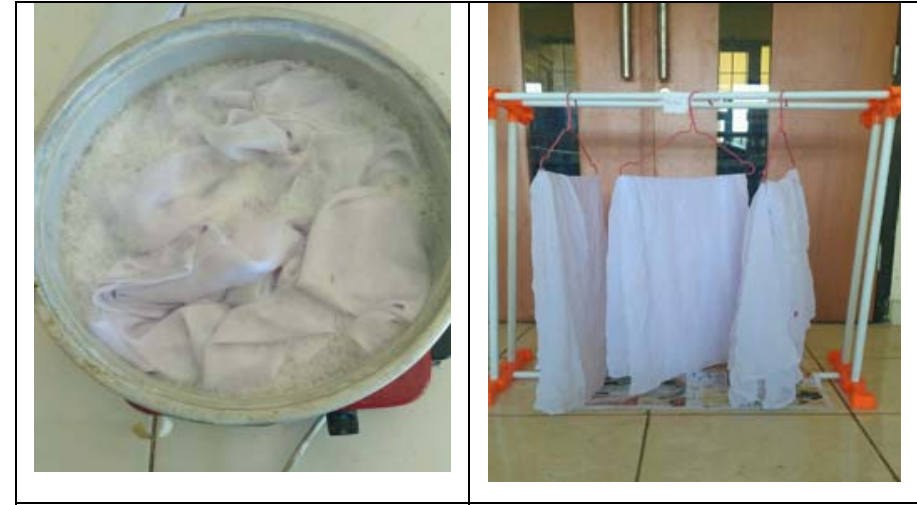

Fig. 3. Fabric pre-treatment process carried out by Najwa SMEs

In the mordanting procedure, positively charged metal ions with more than one valence will be intermediaries for the reaction between hero fabric fibers which are dominated by negatively charged hydroxide groups with specific chromophore groups on each dye compound contained in the cherry and mango leaf, turmeric and brazilwood bark. As shown in Fig. 3, the anthocyanin and tannin groups in the cherry leaf extract, mangiferin in the mango leaf extract, curcuminoid in turmeric extract and brazilin in the brazilwood bark extract, are all compounds that are dominated by negative charge. Without the mordant role as an intermediary, there will be no binding of the dye compound to the fabric fibers.

The tie-dye method applied in the diversification of Najwa hijab staining is included in the pre-mordanting category. Fig. 4 shows the tie-dye staining procedure carried out by Najwa SMEs. After being conditioned in such a way as to create a color barrier on certain parts of the fabric, dye is carried out by 10 times staining, each for $5 \mathrm{~min}$ with a time interval between staining also for $5 \mathrm{~min}$. To lock the color that has reacted with fiber. In Fig. 5 we can see the color shades produced by of each dye extract. The staining results show a significant difference between before and after fixation. This shows the effect of specific chromophore groups that are also present in fixer compounds. Fig. 6 shows the molecular structure of alum, lime and iron (II) sulfate which is used as a fixer in Najwa hijab staining.

The treatment in the fixer will limit the contact of the dye in the fabric fibers with the surrounding environment. Formation of the fixer casing to the staining results will prevent color degradation due to the effect of photolysis by sunlight and thermolysis due to ironing events, the effect of detergents on the washing process and the acid/base of the sweat. Thus, the color intensity on the Najwa hijab can be maintained and the color fastness can be increased. 
Fig. 6 shows the results of the application of the tie-dye procedure in the staining of blush, nutella, mustard, and dark army. The observations showed no significant difference in the resulting color shades. Furthermore, the intensity and color fastness produced varies. The highest color intensity results from a $25 \% \mathrm{~T} / 75 \% \mathrm{BWB}$ dye composition with lime fixation, and vice versa, the lowest color intensity results from a $25 \% \mathrm{CL} / 75 \% \mathrm{BWB}$ composition with alum fixation. In line with this result, blush also produces the lowest fastness. The highest fastness results from alum fixation in mustard color. To improve the fastness especially in blush and nutella colors, multilevel staining and fixation have been applied, and the results are shown in Table 2. The analysis results of the color intensity and fastness showed that the application of multilevel staining and fixation not only succeeded in increasing the color intensity, but also the color fastness.

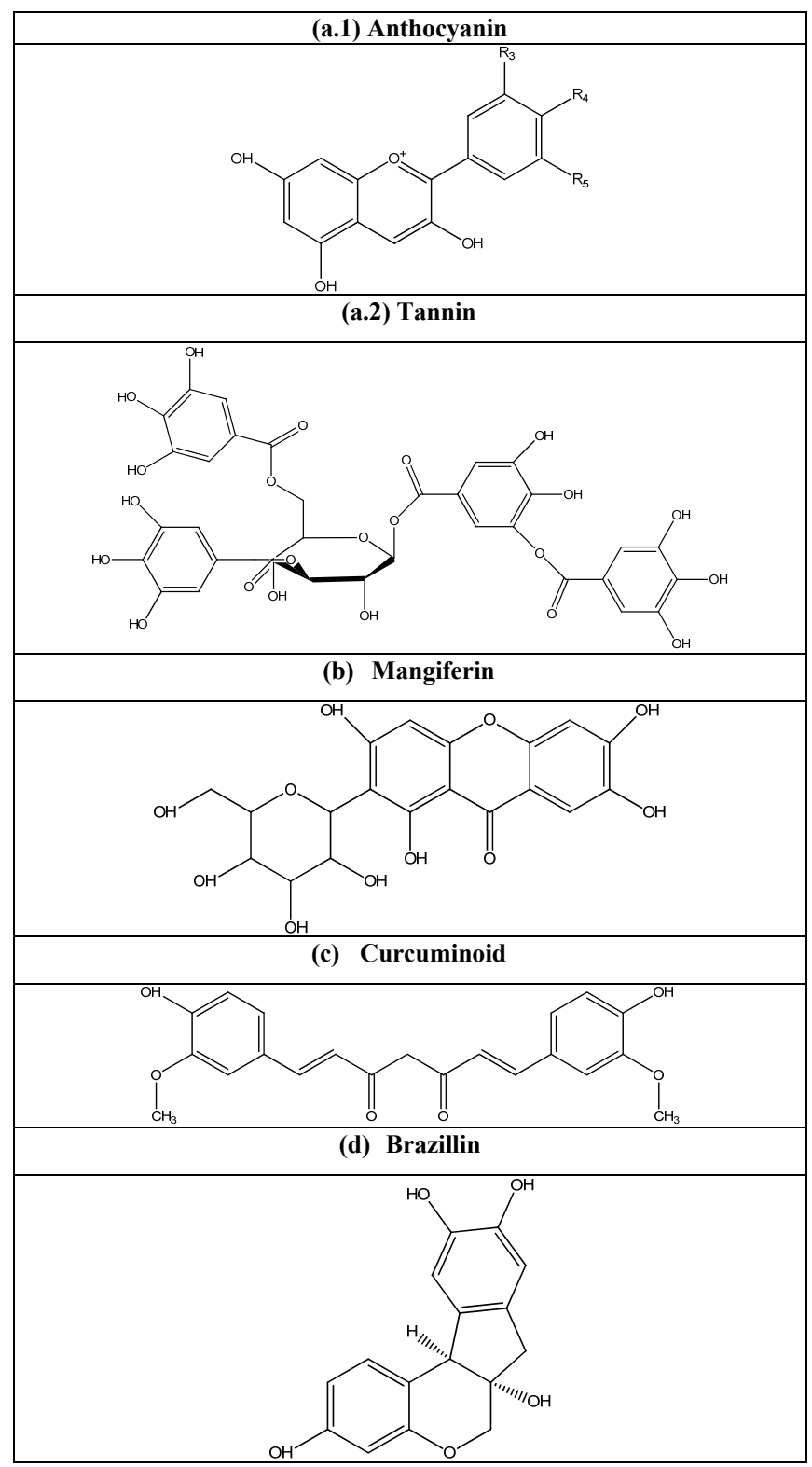

Fig. 4. Molecular structure of: (a) anthocyanin and tannin dyes in cherry leaf extracts; (b) mangiferin in mango leaf extract; (c) curcuminoid in turmeric extract; and (d) brazillin in brazilwood bark extract

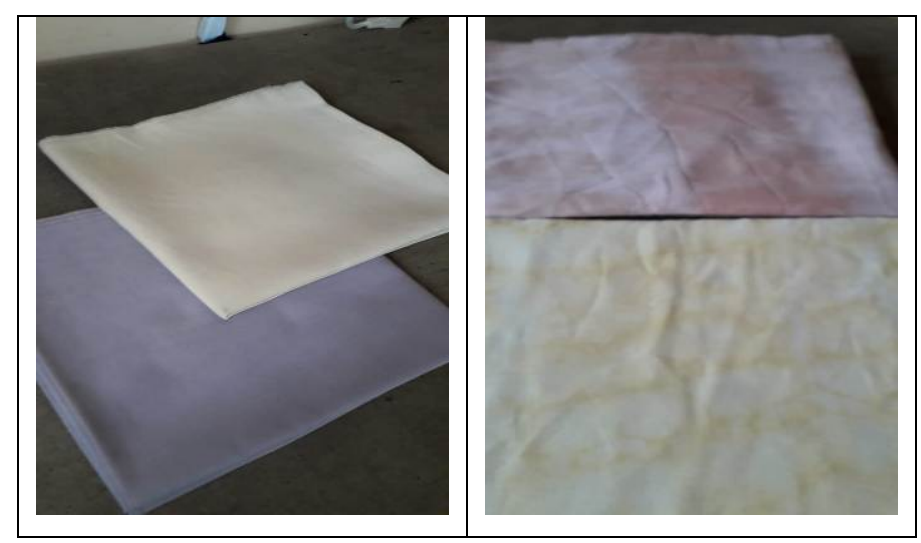

Fig. 5. The staining stages carried out by Najwa Hijab

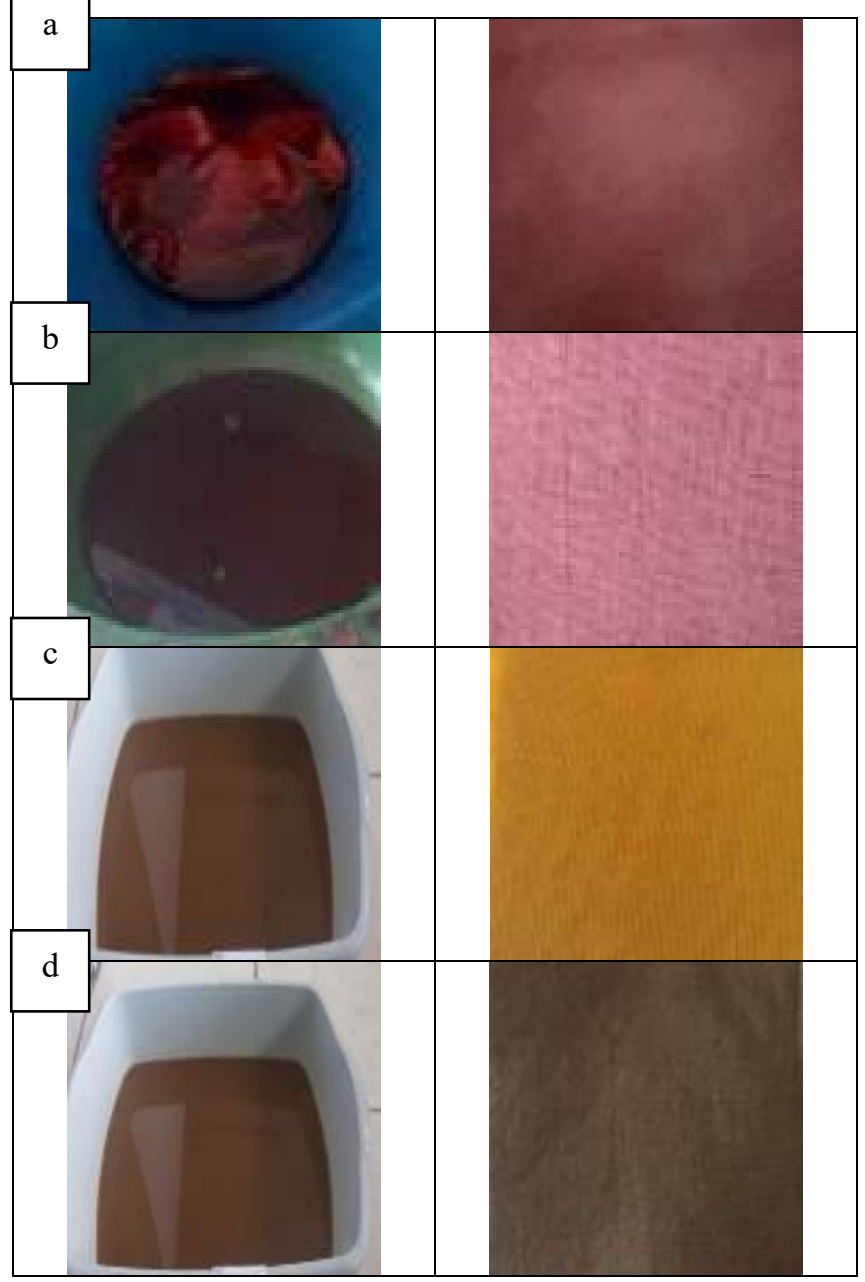

Fig. 6. Blush (a), nutella (b), mustard (c), and dark army (d) color shades produced from each dyes composition 


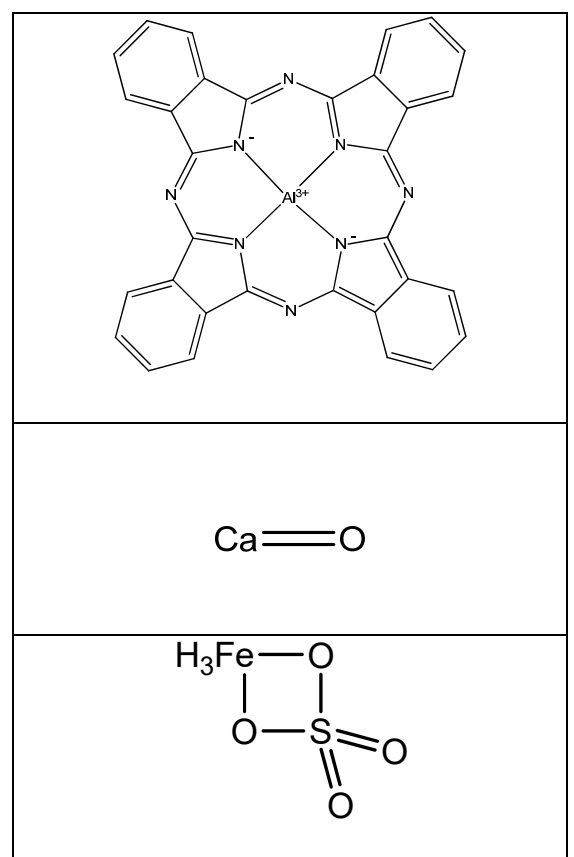

Fig. 7. The molecular structure of: (a) alum; (b) lime; and (c) iron (II) sulfate

TABLE II. THE COLOR INTENSITY WITH A DIFFERENT COMPOSITIONS AND FIXER IN SINGLE STAINING METHOD

\begin{tabular}{llll}
\hline No & Color Type & Color & \\
\cline { 3 - 4 } & & Intensity (\%) & Fastness \\
\hline 1 & Blush & 75.01 & not good enough \\
\hline 2 & Nutella & 87.87 & not good enough \\
\hline 3 & Mustard & 78.64 & Good \\
\hline 4 & Dark Army & 87.36 & Fair \\
\hline
\end{tabular}

TABLE III. THE COLOR INTENSITY WITH A DIFFERENT COMPOSITIONS AND FIXER IN MULTIPLE STAINING METHOD

\begin{tabular}{llll}
\hline No & Color Type & Color & \\
\cline { 3 - 4 } & & Intensity (\%) & Fastness \\
\hline 1 & Blush & 81.76 & fair \\
\hline 2 & Nutella & 90.50 & good enough \\
\hline 3 & Mustard & 85.72 & Good \\
\hline 4 & Dark Army & 87.54 & good enough \\
\hline
\end{tabular}

\section{CONCLUSIONS}

Efforts to diversify staining through the application of the tie-dye method have been carried out to expand the market segment of Najwa hijab products. The series of production stages, from pre-treatment to staining using a combination of dyes from the leaves of cherry and mango, turmeric and brazilwood bark have produced shades of reddish, purplish, brownish and blackish In general, multilevel staining and fixation methods with tie-dye techniques have produced economically potential hijab color quality.

\section{ACKNOWLEDGMENT}

The author thanks Surabaya State University for the financial support provided through the 2019 community partnership program

\section{REFERENCES}

[1] P.K. Das, A.K. Mondal, "Studies on the application of some less known ethno medicinally dye yielding plants for dyeing in cotton cloth with focus on conservation strategies in Paschim medinipur district, West Bengal, India: A new approach.” International Journal of Phytopharmacol., vol.4(1), pp. 54-59, 2013.

[2] S. Islam, M. Shahid, F. Mohammad, "Perspectives for natural product based agents derived from industrial plants in textile applications: a review." J. Clean. Prod., vol. 57, pp. 2-18, 2013.

[3] A. Haji, A. Mousavi Shoushtari, M. Mirafshar, "Natural dyeing and antibacterialactivity of atmospheric-plasma-treated nylon 6 fabric." Color. Technol., vol. 130 (1), pp. 37-42, 2014.

[4] K. Sinha, P.D. Saha, S. Datta, "Extraction of natural dye from petals of flame of forest (Butea monosperma) flower: process optimization using response surface methodology (RSM)." Dyes. Pigm., vol. 94, pp. 212-216, 2012.

[5] S. Adeel, T. Gulzar, M. Azeem, Fazal-ur-Rehman, M. Saeed, I. Hanif, N. Iqbal, "Appraisal of marigold flower based lutein as natural colourant for textile dyeing under the influence of gamma radiations." Radiation Physics and Chemistry, vol. 130, pp. 35-39, 2017.

[6] K.M. Zia, S. Adell, Fazal-ur-Rehman, H. Aslam, M. K. Khosa, M. Zuber, "Influence of ultrasonic radiation on extraction and green dyeing of mordanted cotton using neem bark extract". Journal of Industrial and Engineering Chemistry, vol. 77, pp. 317-322, 2019.

[7] Kusumawati, N. Santoso, A.G., Sianita, M.M., Muslim, S. 2017. Extraction, characterization, and application of natural dyes from the fresh mangosteen (Garcinia mangostana L.) peel. International Journal on Advanced Science, Engineering, Information Technology, 7(3): pp. 878-884

[8] C. Mayusoh, "The art of designing, fabric pattern by tie-dyeing with natural dyes." Procedia - Sosial and Behavioral Sciences, vol. 197, pp. 1472-1480, 2015.

[9] Kusumawati, N., Muslim, S., Kistyanto, A. 2016. Operational conditions optimization on blacu fabric dyeing technology (case study: mordanting influence on naphtol color quality and mechanical strength of blacu fiber. Research Journal of Pharmaceautical Biological and Chemical Sciences 7(5): pp. 33-42.

[10] Kusumawati, N., Koestiari, T., Santoso, A.B. 2015. The influence of washing process using TRO on indigosol dyeing quality, leaching percentage, and mechanical strength of mori fabric. Research Journal of Pharmaceautical Biological and Chemical Sciences 6(6): pp. 5563.

[11] Kusumawati, N., Samik, Santoso, A.B., Wijiastuti, A. 2018. Development of textile natural dyeing using hybrid dyes from mango leaves turmeric. Advances in Engineering Research, 171: pp. 50-55.

[12] Kusumawati, N., Mufida, L., Annisa, R.A. 2018. Pewarna alami untuk tekstil. Surabaya : Unesa University Press. 